\title{
Clinical pharmacogenomic testing of KRAS, BRAF and EGFR mutations by high resolution melting analysis and ultra-deep pyrosequencing
}

Emma Borràs ${ }^{1}$ Ismael Jurado², Imma Hernan ${ }^{1}$, María José Gamundi ${ }^{1}$, Miguel Dias ${ }^{1}$, Isabel Martî ${ }^{1}$, Begoña Mañé , Àngels Arcusa ${ }^{3}$, José AG Agúndez ${ }^{4}$, Miguel Blanca ${ }^{5}$ and Miguel Carballo ${ }^{1 *}$

\begin{abstract}
Background: Epidermal growth factor receptor (EGFR) and its downstream factors KRAS and BRAF are mutated in several types of cancer, affecting the clinical response to EGFR inhibitors. Mutations in the EGFR kinase domain predict sensitivity to the tyrosine kinase inhibitors gefitinib and erlotinib in lung adenocarcinoma, while activating point mutations in KRAS and BRAF confer resistance to the anti-EGFR monoclonal antibody cetuximab in colorectal cancer. The development of new generation methods for systematic mutation screening of these genes will allow more appropriate therapeutic choices.
\end{abstract}

Methods: We describe a high resolution melting (HRM) assay for mutation detection in EGFR exons 19-21, KRAS codon 12/13 and BRAF V600 using formalin-fixed paraffin-embedded samples. Somatic variation of KRAS exon 2 was also analysed by massively parallel pyrosequencing of amplicons with the GS Junior 454 platform.

Results: We tested 120 routine diagnostic specimens from patients with colorectal or lung cancer. Mutations in KRAS, BRAF and EGFR were observed in $41.9 \%, 13.0 \%$ and $11.1 \%$ of the overall samples, respectively, being mutually exclusive. For KRAS, six types of substitutions were detected (17 G12D, 9 G13D, 7 G12C, 2 G12A, 2 G12V, 2 G12S), while V600E accounted for all the BRAF activating mutations. Regarding EGFR, two cases showed exon 19 deletions (delE746-A750 and delE746-T751insA) and another two substitutions in exon 21 (one showed L858R with the resistance mutation T590M in exon 20, and the other had P848L mutation). Consistent with earlier reports, our results show that KRAS and BRAF mutation frequencies in colorectal cancer were $44.3 \%$ and $13.0 \%$, respectively, while EGFR mutations were detected in $11.1 \%$ of the lung cancer specimens. Ultra-deep amplicon pyrosequencing successfully validated the HRM results and allowed detection and quantitation of KRAS somatic mutations.

Conclusions: HRM is a rapid and sensitive method for moderate-throughput cost-effective screening of oncogene mutations in clinical samples. Rather than Sanger sequence validation, next-generation sequencing technology results in more accurate quantitative results in somatic variation and can be achieved at a higher throughput scale.

\section{Background}

The epidermal growth factor receptor (EGFR) plays a key role as a receptor tyrosine kinase (TK), controlling several signalling pathways that stimulate cell growth, proliferation and survival. Mutations involving the EGFR axis can cause its constant activation, leading to uncontrolled cell proliferation. Not surprisingly, EGFR

\footnotetext{
* Correspondence: mcarballo@cst.cat

${ }^{1}$ Molecular Genetics Unit, Hospital de Terrassa, Ctra. Torrebonica, 08227 Terrassa, Spain

Full list of author information is available at the end of the article
}

mutations have been identified in several types of cancer and it is a target of many anticancer therapies, including small-molecule TK inhibitors (e.g., gefitinib and erlotinib for lung cancer) and monoclonal antibodies (e.g., cetuximab and panitumumab for colon cancer). Moreover, the mutational status of EGFR and its downstream molecules have implications for the responsiveness to treatment and prognosis.

Somatic mutations in the kinase domain of the EGFR gene (exons 18-21) are reportedly associated with sensitivity of lung cancers to TK inhibitors [1-5]. About $90 \%$

\section{Biomed Central}


of the sensitising mutations are in-frame deletions in exon 19, affecting the conserved amino acids LREA, and the point mutation L858R in exon 21. Such EGFR mutations increase sensitivity to TK inhibitors, most likely through induction of critical structural modifications of the ATP-binding site in the TK domain. Unfortunately, during the course of treatment, some patients eventually develop acquired resistance to TK inhibitors, often due to the secondary T790M mutation in EGFR exon 20 $[6,7]$. Furthermore, a significant proportion of cancer patients show no benefit from anti-EGFR therapies because of the independent activation of downstream signalling, especially the Ras/Raf/MAPK pathway. Mutations in the KRAS gene occur early in the development of many cancers and are found in more than $90 \%$ of pancreatic adenocarcinomas, $40 \%$ of colorectal cancers (CRC) and $33 \%$ of non-small cell lung carcinomas (NSCLC) [8]. Commonly restricted to codon 12/13 in exon 2, and rarely codons 59 and 61 in exon $3[8,9]$, these mutations cause impaired GTPase activity and result in a continual stimulus for cellular proliferation. Somatic KRAS mutations have been associated with resistance to EGFR-targeted agents in lung cancer and metastatic CRC [10], and are mutually exclusive with EGFR mutations in large series of NSCLC $[4,11]$.

Likewise, KRAS and BRAF mutations are inversely associated in $C R C$, consistent with the fact that both induce similar effects through the same pathway, since the B-Raf protein kinase is activated by membranebound Ras. BRAF mutations are found in many types of cancer, predominantly in up to $80 \%$ of melanoma and nevi [12]. V600E amino acid substitution in the activation segment accounts for $90 \%$ of $B R A F$ mutations and is significantly associated with microsatellite instability [13]. Data from retrospective studies suggest that mutated $B R A F$, which is present in $5-10 \%$ of colorectal tumours, can affect the response to anti-EGFR monoclonal antibodies in patients with wild type KRAS [14-16], 40-60\% of whom do not respond to such therapy [17].

Current guidelines in the US state that patients with metastatic CRC being considered for EGFR-targeted therapies should be tested for KRAS and BRAF mutations [18], and recommend EGFR testing for patients with advanced NSCLC to predict response to first-line TK inhibitors [19,20]. Moreover, the European Society of Pathology has started a helpdesk and a quality assurance program for KRAS testing in CRC [21]. Rapid, sensitive and reliable methods for mutation detection are therefore required for stratification of patients to receive molecularly targeted treatment.

High-resolution melting (HRM) is a recently developed technique that shows great potential for scanning germline and somatic mutations [22]. This method is based on a real-time PCR amplification in the presence of a saturating intercalating fluorescent dye and subsequent separation of the DNA strands in a temperature gradient, during which the fluorescence is registered with high resolution. If there are mutant alleles in the sample, the formed heteroduplexes of wild type and mutant alleles are separated at lower temperatures, generating a different melting pattern. The HRM assay is useful as a prescreening test and positive samples should be sequenced to identify the specific nucleotide alterations. However, at the limit of somatic mutation detection with real time PCR technologies, sequencing by Sanger is not suitable as a confirmatory method and validation of results may require a more quantitative sequence variation assay.

Ultra-deep sequencing is undoubtedly the most sensitive technology currently available for mutation scanning. This method is well suited for detection of somatic mutations, which may be present in a small fraction of tumour cells within a background of normal tissue. Benchtop sequencers, like the GS Junior 454, have brought high-throughput sequencing to molecular diagnostic laboratories, and development of cancer mutation detection assays using this platform is therefore of special interest.

Herein, we describe a HRM assay to identify hotspot mutations in EGFR, KRAS and BRAF oncogenes, and investigate the potential application of ultra-deep amplicon pyrosequencing for somatic variation detection in clinical samples.

\section{Methods}

\section{Patient samples}

Informed consent was obtained from all patients prior to the study, which was conducted in accordance with the Helsinki Declaration and approved by the internal Clinical Research Ethics Committee (CEIC) of the Hospital de Terrassa (Spain). Analysis of KRAS, BRAF and $E G F R$ mutations was performed in 120 formalin-fixed paraffin-embedded (FFPE) tumour samples, according to the clinicians' orders. The specimens included $81 \mathrm{CRCs}$, 27 lung carcinomas and 12 metastatic tumours from primary colorectal $(n=2)$ or lung $(n=10)$ cancers. Before starting the routine mutation testing, an additional series of 32 CRC samples was used to compare our results with those obtained in another centre using the DxS TheraScreen KRAS mutation kit (Qiagen, Izasa, Barcelona, Spain). For KRAS mutation screening by ultra-deep pyrosequencing, five known CRC samples were selected, including two wild type (33K and $75 \mathrm{~K}$ ) and three mutants: $51 \mathrm{~K}$ (G12V), $81 \mathrm{~K}$ (G12D apparently heterozygous) and 97K (G12C).

\section{DNA extraction}

Tumour-rich areas marked by the pathologist on a hematoxylin and eosin histologic section were manually 
macrodissected by block trimming or target tissue dissection, and up to 10 sections of $5 \mu \mathrm{m}$ thickness were collected in a microtube for genetic testing. In general, the estimated percentage of cancer cells in the selected tissue was greater than $70 \%$ of total cells. Genomic DNA was extracted using the QIAamp DNA FFPE Tissue Kit (Qiagen), quantitated with the Epoch MultiVolume Spectrophotometer System (BioTek, Izasa, Barcelona, Spain), and stored at $-20^{\circ} \mathrm{C}$ until use.

\section{Mutation screening by HRM Design of HRM primers}

At first, existing primer pairs from previously published HRM studies were tested to ensure good discrimination between wild type and mutant samples in our platform. If they were inappropriate or unavailable, new primers were designed. Since FFPE-derived DNA is often fragmented and because the influence of variation in the melting curve shape decreases with an increasing sequence length, short amplicons were preferred. The inclusion of single nucleotide polymorphisms (SNPs) within the amplicon was minimised and, if the primer was placed over a sequence variant, mismatched bases with no allelic preference were introduced. Primer pairs for all target regions were analysed for specificity and to ensure similar melting temperatures using PrimerBLAST software [23], and DNA melting predictions were performed with the web servers Stitchprofiles.uio. no [24] and DINAMelt [25]. As shown in Table 1, existing primers were used for KRAS [26] and EGFR exons 19 and 21 [27], and newly designed primers for EGFR exon 20 and $B R A F$. All the amplicons spanned $\leq 250 \mathrm{bp}$ and covered most common mutations.

Table 1 HRM primer sequences

\begin{tabular}{|c|c|c|c|}
\hline Gene & Exon & Primer sequence & $\begin{array}{l}\text { Amplicon } \\
\text { size }\end{array}$ \\
\hline \multirow[t]{2}{*}{ KRAS } & 2 & $\begin{array}{l}\text { F: 5'-GGCCTGCTGAAAATGACTGAATATAA- } \\
3^{\prime}\end{array}$ & 170 bp [26] \\
\hline & & R: 5'-AAAGAATGGTCCTGCACCAGTA-3' & \\
\hline \multirow[t]{2}{*}{ BRAF } & 15 & $\begin{array}{l}\text { F: 5'- } \\
\text { TCATGAAGACCTCACAGTAAAAATAGG-3' }\end{array}$ & $164 \mathrm{bp}$ \\
\hline & & R: 5'-AGCAGCATCTCAGGGCCAAA-3' & \\
\hline \multirow[t]{2}{*}{ EGFR } & 19 & F: 5'-GTGCATCGCTGGTAACATCCA-3' & 250 bp§ [27] \\
\hline & & R: 5'-AAAGGTGGGCCTGAGGTTCA-3' & \\
\hline \multirow[t]{2}{*}{ EGFR } & 20 & F: 5'-ACCTCCACCGTGCA(T*)CTCAT-3' & $128 \mathrm{bp}$ \\
\hline & & $\begin{array}{l}\text { R: 5'- ATTACCTTTGCGATCTGAACACACC } \\
-3^{\prime}\end{array}$ & \\
\hline \multirow[t]{2}{*}{ EGFR } & 21 & F: 5'-CCTCACAGCAGGGTCTTCTCTG-3' & 210 bp§ [27] \\
\hline & & R: 5'-TGGCTGACCTAAAGCCACCTC-3' & \\
\hline
\end{tabular}

\section{HRM assay}

Samples were assayed in duplicate using the LightCycler 480 system (Roche, Barcelona, Spain). Each $10 \mu \mathrm{l}$ reaction contained about 70 ng DNA diluted in $1.8 \mu \mathrm{l}, 1 \mathrm{x}$ LightCycler HRM Master Reaction Mix (Roche), $3 \mathrm{mM}$ $\mathrm{MgCl}_{2}$, and $200 \mathrm{nM}$ primers (HPLC purified). Wild type and non-template control samples were added for each amplicon tested. The same touchdown PCR program and melting conditions were used for all amplicons: $95^{\circ}$ $\mathrm{C}$ for $10 \mathrm{~min} ; 45$ cycles of $95^{\circ} \mathrm{C}$ for $10 \mathrm{~s}, 62-54^{\circ} \mathrm{C}\left(1^{\circ} \mathrm{C} /\right.$ cycle) for $15 \mathrm{~s}$ and $72^{\circ} \mathrm{C}$ for $10 \mathrm{~s} ; 95^{\circ} \mathrm{C}$ for $1 \mathrm{~min} ; 40^{\circ} \mathrm{C}$ for $1 \mathrm{~min}$; a melt of $72-92^{\circ} \mathrm{C}\left(0.01^{\circ} \mathrm{C} / \mathrm{s}, 45\right.$ acquisitions $/^{\circ}$ $\mathrm{C})$; and $40^{\circ} \mathrm{C}$ for $10 \mathrm{~s}$. Data were acquired and analysed with the accompanying Gene Scanning software. Normalised and temperature-adjusted melting curves of test samples and wild type controls were compared, and samples with an aberrant melting pattern were judged to carry a somatic mutation.

\section{Sanger sequencing}

Amplified products of mutation positive or ambiguous samples were recovered from the plate, column purified with the High Pure PCR Product Purification Kit (Roche), and submitted to StabVida (Oeiras, Portugal) for direct sequencing on a 3730XL ABI DNA sequencer (Applied Biosystems, Foster City, CA) using the Big Dye terminator V1.1 DNA sequencing kit and the HRM primers.

\section{HRM sensitivity testing}

To test the analytical sensitivity of our HRM assay we used patient FFPE-derived DNA, assuming that a sample carrying a heterozygous (Ht) mutation contained 50\% mutant alleles. Genomic DNA of the KRAS mutant sample $81 \mathrm{~K}$ (G12D Ht) was mixed with wild type DNA of sample $75 \mathrm{~K}$ in dilutions containing $50 \%, 25 \%, 10 \%, 5 \%$, $2.5 \%$ and $0 \%$ mutant alleles. Moreover, decreasing amounts of template DNA were used to investigate the limits of KRAS mutation detection. Samples 81K (G12D $\mathrm{Ht}$ ) and $100 \mathrm{~K}$ (wild type) were compared using 40, 20, 10 and 5 ng DNA.

\section{Mutation screening by ultra-deep pyrosequencing Design of fusion primers}

The primers used to generate KRAS amplicon libraries were composed of three parts fused together (Figure 1). The 5'-portion was a 25-mer corresponding to the adaptors $\mathrm{A}$ and $\mathrm{B}$ required by the 454 sequencing system and ending with the sequencing key "TCAG". Multiplex Identifiers of $10 \mathrm{bp}$ (MIDs 1-5 from the standard 454 set), placed after the key, were used to barcode the different samples. And the 3'-portion was designed to anneal with a specific sequence on either side of KRAS exon 2, resulting in a 409 bp amplicon (total size with adaptors and MIDs). The presence of the same MID tag in the forward and reverse primer of each pair, and the 


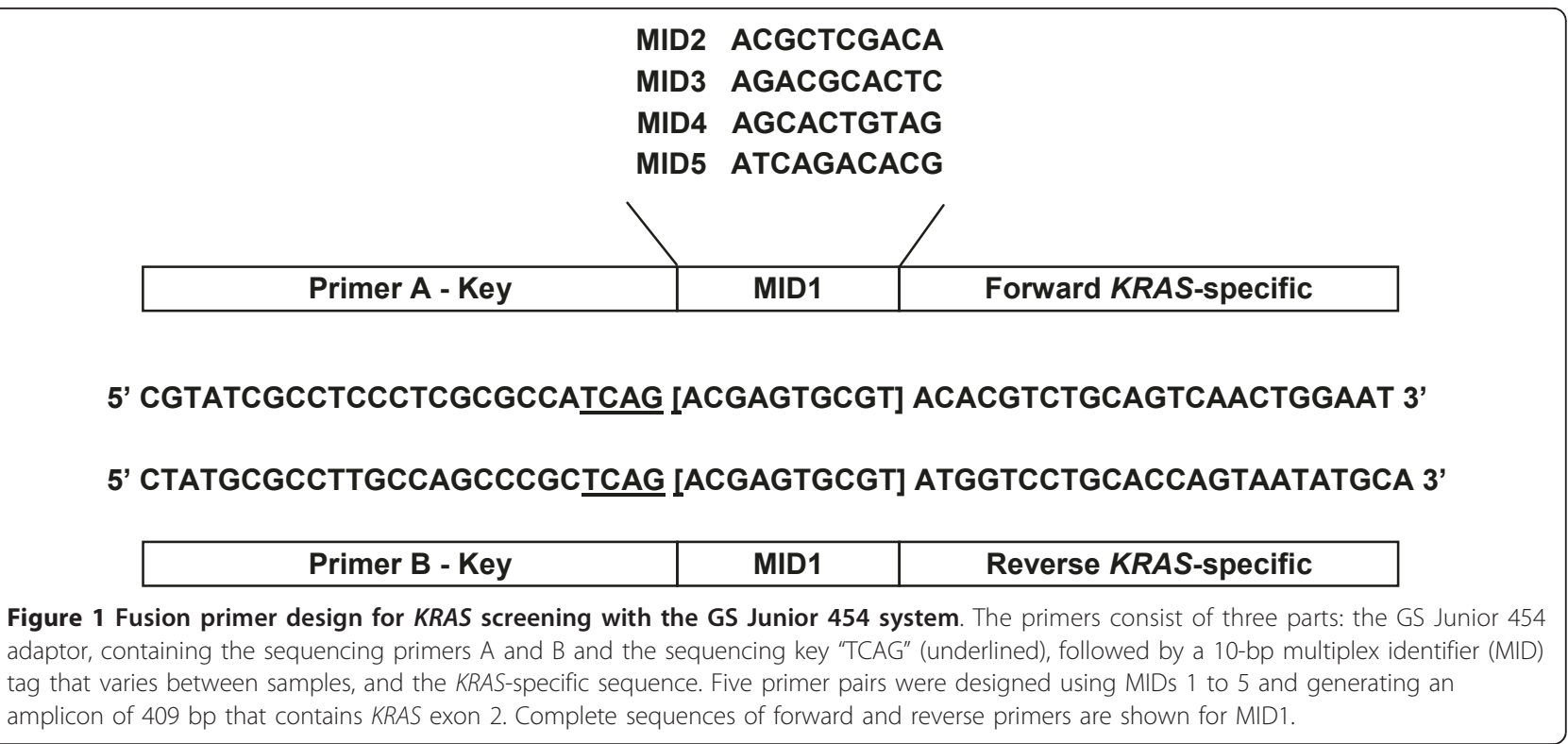

length of the generated amplicons, within the 400-500 bp range offered by Titanium chemistry, allowed for bidirectional sequencing with primers $\mathrm{A}$ and $\mathrm{B}$.

\section{Amplicon preparation}

PCR was conducted in a $50 \mu$ final volume containing: 1x PCR buffer, $1.5 \mathrm{mM} \mathrm{MgCl}_{2}, 500 \mathrm{nM}$ fusion primers, $2 \mu \mathrm{l}$ genomic DNA (0.3-1.5 $\mu \mathrm{g}), 200 \mu \mathrm{M}$ dNTPs, $2.5 \mathrm{U}$ of BioTaq polymerase (Bioline, Ecogen, Barcelona, Spain) and PCR grade water. Program conditions were: $5 \mathrm{~min}$ at $95^{\circ} \mathrm{C}$; followed by 35 cycles of $30 \mathrm{~s} \mathrm{~min} \mathrm{at} 95^{\circ}$ $\mathrm{C}, 30 \mathrm{~s}$ at $59^{\circ} \mathrm{C}$ and $30 \mathrm{~s}$ at $72^{\circ} \mathrm{C}$; and $8 \mathrm{~min}$ at $72^{\circ} \mathrm{C}$. PCR products were analysed by $1.5 \%$ agarose gel electrophoresis and column purified with the High Pure PCR Purification Kit (Roche). Amplicons were further purified with Agencourt AMPure XP beads (Beckman Coulter, Izasa, Barcelona, Spain), and quantitated by fluorometry in a LightCycler 480 instrument (Roche) using the Quant-iT PicoGreen dsDNA Assay Kit (Invitrogen), as described by the manufacturer. The five amplicon libraries, with concentrations ranging from $6.63 \times 10^{9}$ to $5.05 \times 10^{10}$ molecules/ $\mu \mathrm{l}$, were equimolarly pooled to create a KRAS multiplexed library at $1 \times 10^{7}$ molecules/ $\mu \mathrm{l}$.

\section{Pyrosequencing}

To make the most of the capacity of the sequencing plate, this library was mixed with another of $B R C A$ amplicons to be sequenced in a single run. Emulsion PCR of the combined library was carried out using the GS Junior Titanium emPCR Kit (Lib-A) and pyrosequenced on the GS Junior 454 platform (Roche). An input of 3 molecules of library DNA per capture bead was used and 500,000 enriched beads were loaded on the instrument. The library was sequenced in a
Titanium PicoTiterPlate (PTP) with Titanium reagents, and base calling was performed with the amplicon filter settings.

Data analysis

Processed and quality-filtered reads were analysed with the GS Amplicon Variant Analyzer. The KRAS amplicon (excluding adaptors and MIDs) was used as the reference to align amplicon reads, template-specific portions of the fusion primers were considered as the forward and reverse primer, and the known mutations of the samples selected were defined as substitutions relative to the reference sequence. Correspondence of samples and MID tags was specified and, as the same MID was present in both orientations, an "either" encoding multiplexer was used to demultiplex the reads.

\section{Results}

\section{Validation and sensitivity of KRAS HRM assay}

Mixtures of KRAS mutant (G12D Ht) and wild type DNAs were used to test the analytical sensitivity of the HRM assay. Figure 2 shows the difference plots (A) and melting peaks (B) for different dilutions of mutant DNA, and demonstrates that this assay can detect $2.5 \%$ mutant alleles, which corresponds to $5 \%$ tumour cells carrying a heterozygous mutation.

Wild type KRAS amplicons have a biphasic melting curve due to the presence of different melting domains (Figure 2-A). Accordingly, two melting peaks are observed in the first-derivative plot of normal samples, while mutant samples show another peak, generated by heteroduplexes melting, the height of which is proportional to the fraction of cells bearing the mutation (Figure 2-B). This peak alters considerably the characteristic 

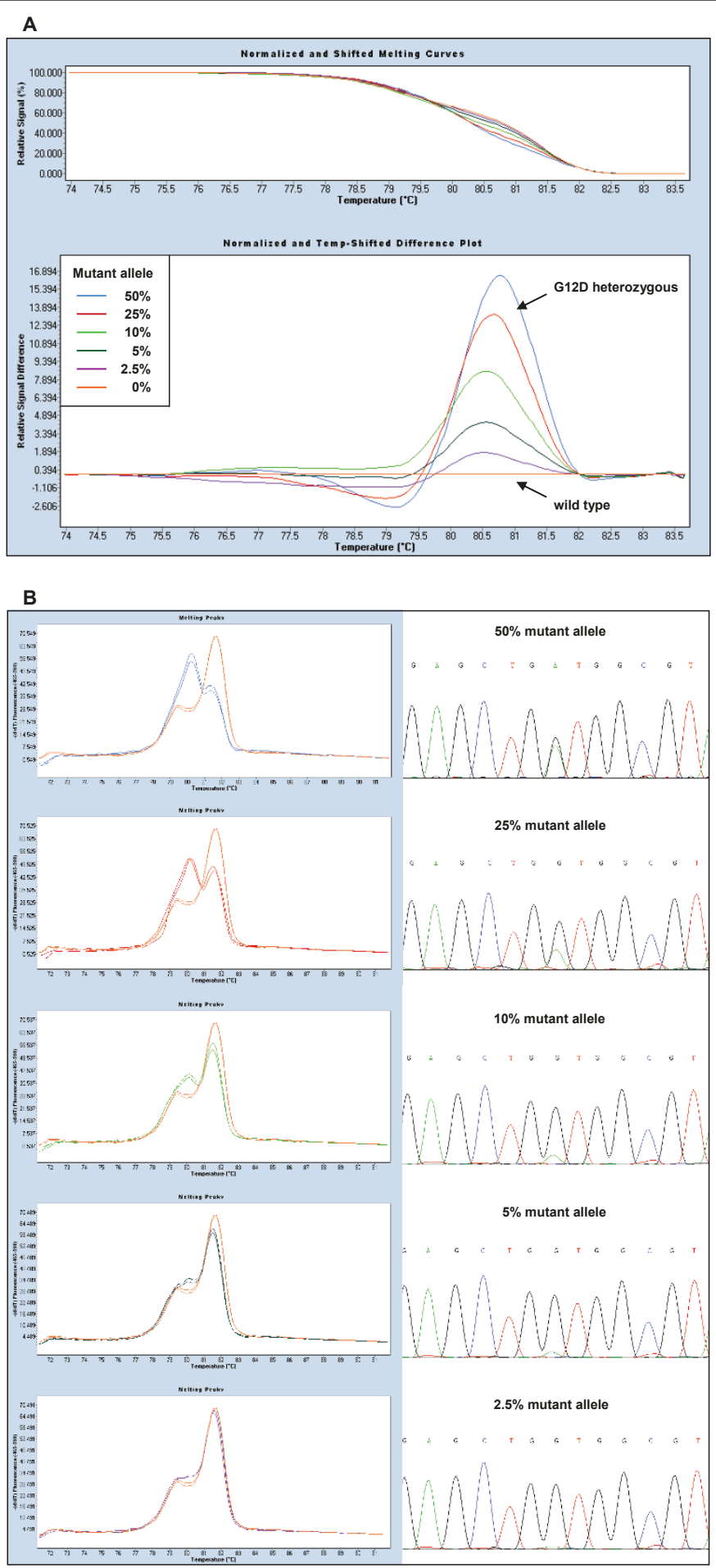

Figure 2 Sensitivity of the KRAS HRM assay. Mixtures of mutant (G12D heterozygous) and wild type genomic DNA samples reveal gradual curves. A) Adjusted melting curves (top) and differential plots (bottom) showing the presence of 50\%, 25\%, 10\%, 5\%, 2.5\% and 0\% mutant alleles. B) Melting peaks of mutant sample dilutions compared to the wild type control (left) and corresponding sequence traces (right). In the chromatograms, mutation peaks can be distinguished from the background because they are symmetrical and vertically aligned with the wild type peaks. 
shape of the curve, even with low amounts of mutant DNA. Thereby, the presence of $2.5 \%$ mutant alleles is visible in the graph but not in the chromatogram (Figure 2-B), where the peaks can be confused with the background, consistent with the higher sensitivity of HRM compared to direct Sanger sequencing.

On the other hand, the limited amount of FFPE tissue is a common problem, especially when working with lung cancer specimens. To investigate the lower limit of KRAS mutation detection, the HRM assay was performed with template DNA amounts of G12D Ht and wild type samples ranging from 40 to $5 \mathrm{ng}$. Mutant samples showed an abnormal profile across the entire range of template amounts tested and could be readily identified (not shown). Therefore, as little as $5 \mathrm{ng}$ (or even less) of mutant DNA would be enough to detect the KRAS mutation in non-degraded samples.

\section{KRAS, BRAF and EGFR mutation detection by HRM}

A total of 120 routine diagnostic FFPE samples from patients with colorectal $(\mathrm{n}=81)$, lung $(\mathrm{n}=27)$ and other $(\mathrm{n}=12)$ cancers were screened for mutations in the EGFR pathway. Melting patterns and sequence traces of representative mutations for each amplicon are depicted in Figure 2-B and Figure 3, with Table 2 showing the results obtained.

For KRAS, six different substitutions were detected at codon $12 / 13$, predominantly G12D, whereas V600E accounted for all the BRAF mutations found (Table 2). Five mutations in the $E G F R$ gene were detected in four patients. Two patients had exon 19 deletions (delE746A750 and delE746-T751insA), one patient showed the common sensitising mutation L858R in exon 21 together with the resistance mutation T590M in exon 20 , and the other harboured the uncommon exon 21 point mutation $\mathrm{P} 848 \mathrm{~L}$, which appears to behave as a
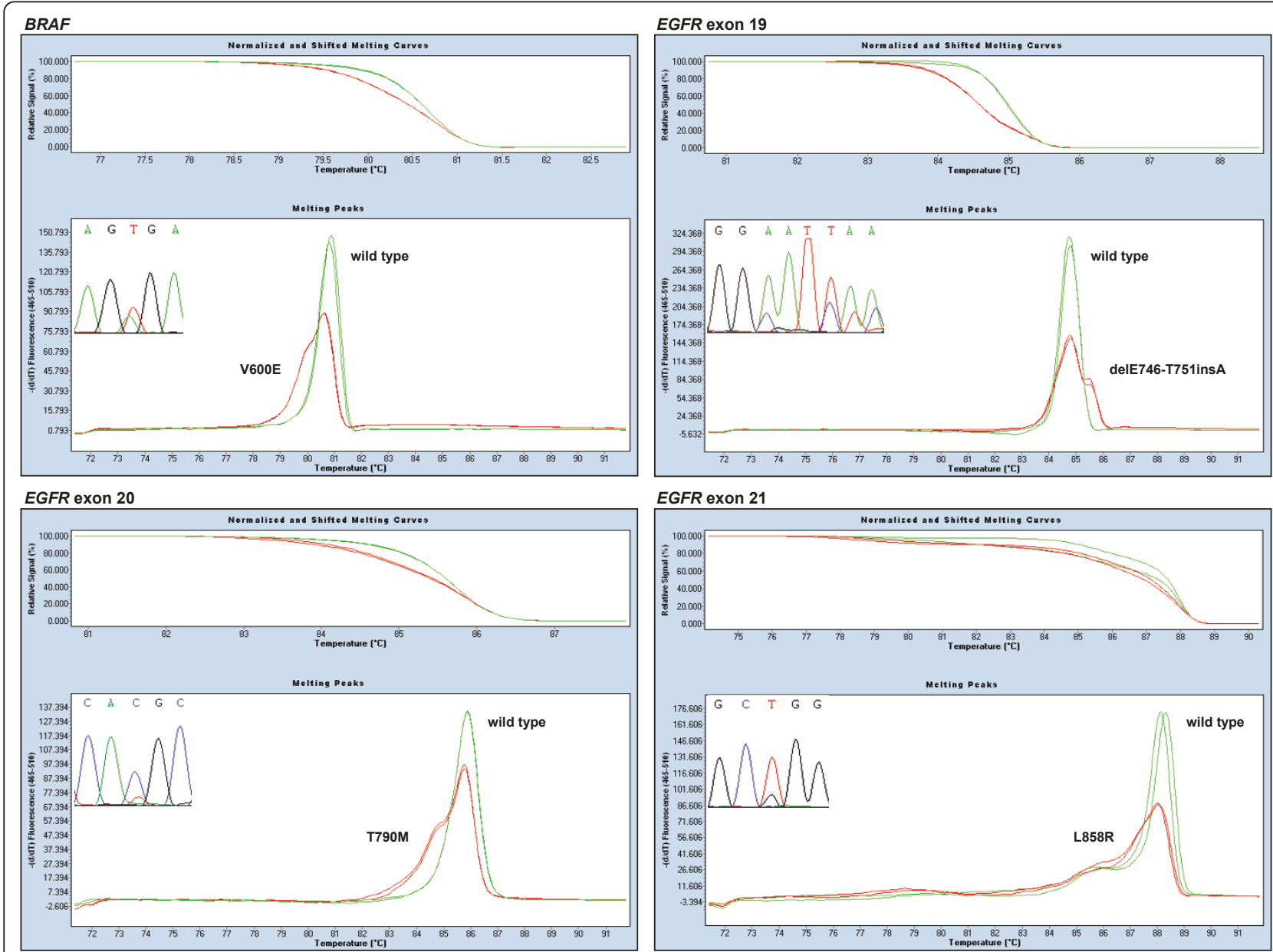

Figure 3 Panel of HRM assays and sequence traces for BRAF and EGFR. Normalised shifted melting curves and melting peaks of HRM amplicons are compared between wild type (green) and representative mutant samples (red). Mutant samples show left-shifted curves and aberrant melting profiles, with a lower homoduplex peak and a more or less visible heteroduplex peak on its left, except for EGFR exon 19 deletions, in which the sequence of the deleted allele has a higher melting temperature. 
Table 2 Variants detected by HRM analysis

\begin{tabular}{|c|c|c|c|c|}
\hline Gene & Nucleotide & Protein & $\begin{array}{l}\text { No. } \\
\text { detected }\end{array}$ & $\begin{array}{l}\text { Total } \\
\%\end{array}$ \\
\hline \multirow[t]{8}{*}{ KRAS } & $35 G>A$ & G12D & 17 & 18.3 \\
\hline & $38 \mathrm{G}>\mathrm{A}$ & G13D & 9 & 9.7 \\
\hline & $34 \mathrm{G}>\mathrm{T}$ & G12C & 7 & 7.5 \\
\hline & $35 G>C$ & G12A & 2 & 2.2 \\
\hline & $35 G>T$ & G12V & 2 & 2.2 \\
\hline & $34 \mathrm{G}>\mathrm{A}$ & G12S & 2 & 2.2 \\
\hline & Total no. of cases with & mutated KRAS & 39 & 41.9 \\
\hline & Total no. of cases & & 93 & 100 \\
\hline \multirow[t]{3}{*}{ BRAF } & 1799T > A & V600E & 7 & 13.0 \\
\hline & Total no. of cases with & mutated BRAF & 7 & 13.0 \\
\hline & Total no. of cases & & 54 & 100 \\
\hline \multirow[t]{6}{*}{ EGFR } & 2236-2250del15 & delE746-A750 & 1 & 2.8 \\
\hline & 2237-2252del16 & $\begin{array}{l}\text { delE746- } \\
\text { T751insA }\end{array}$ & 1 & 2.8 \\
\hline & $\begin{array}{l}2369 C>T, 2573 T> \\
G\end{array}$ & T790M, L858R & 1 & 2.8 \\
\hline & $2543 C>T$ & P848L & 1 & 2.8 \\
\hline & Total no. cases with m & lutated $E G F R$ & 4 & 11.1 \\
\hline & Total no. of cases* & & 36 & 100 \\
\hline
\end{tabular}

* Exon 20 was not analysed in 13 samples.

functionally silent polymorphism [28] (Table 2). In addition, a SNP in exon $21(2508 \mathrm{C}>\mathrm{T}$ at R836) was also detected in one patient.

All the mutant samples identified by HRM were confirmed by direct Sanger genomic sequencing. In addition, 28 random samples identified as wild type in the HRM analysis, as well as three samples with ambiguous melting patterns due to poor amplification, showed wild type chromatograms. Therefore, using HRM and Sanger sequencing, no false positives were detected in the 51 mutations assessed and no false negatives were found among the 31 cases analysed.

Only three specimens that showed insufficient amplification in the HRM assay because of the low amount or quality of the starting material were subjected to standard PCR amplification using the HRM primers followed by direct sequencing. Minimisation of reaction-to-reaction variability was especially important in these cases. To standardise sample preparation, we quantitated the extracted DNA by spectrophotometry, adjusted the samples to the same concentration and used the same amount of template in each reaction. Even though $5 \mathrm{ng}$ is allowed for proper amplification of good quality samples, an excess of template (about $70 \mathrm{ng}$ ) was used to overcome the challenge posed by compromised DNA quality. Previous reports consistently suggest that inclusion of $>30 \mathrm{ng}$ purified DNA increases the success rate up to 96\% [29]. For good HRM analysis, amplification curves were checked to produce a crossing point $<30$ and to reach a similar plateau height. If duplicates of a sample showed different melting patterns, the assay was repeated for that sample. And when insufficient amplification precluded detection of subtle differences between small melting peaks, PCR products were sequenced to avoid false negative results.

\section{KRAS mutation detection by ultra-deep pyrosequencing}

A pilot experiment was set up to evaluate the feasibility of applying amplicon pyrosequencing to detect somatic variation in FFPE tumour samples. With this aim, two wild type and three known mutant samples were selected for screening the entire KRAS exon 2.

A multiplexed KRAS amplicon library was prepared, mixed with $B R C A$ amplicons, and subsequently sequenced with GS Junior 454, achieving a throughput of 26 million high-quality filtered bases and $7.7 \times 10^{4}$ filtered reads (41.3\% key pass reads) for the library (containing the "TCAG" key). Considering only the KRAS amplicons, 9 to 12 thousand reads were obtained for each of the five samples selected (Figure 4).

The known KRAS genotype was validated in all cases, and frequencies of the previously defined variants were calculated from combined data of forward and reverse reads. Samples $33 \mathrm{~K}$ and $75 \mathrm{~K}$ were confirmed as wild type, while mutant samples showed the following variation frequencies: $22.8 \% \mathrm{G} 12 \mathrm{~V}$ for $51 \mathrm{~K}, 35.7 \% \mathrm{G} 12 \mathrm{C}$ for $97 \mathrm{~K}$, and $38.9 \%$ G12D for $81 \mathrm{~K}$. No additional variants were detected above the minimum frequency setting of $1 \%$ even though a DNA polymerase enzyme without proofreading activity was used in the PCR amplification. An illustrative example of the sequence variations detected within sample 97K is shown in Figure 4.

In the case of sample $81 \mathrm{~K}$, considered heterozygous on the basis of the Sanger chromatogram (Figure 2-B, top right), the observed percentage of $38.9 \%$ mutant alleles is in accordance with the estimated ratio of $85 \%$ tumour cells in the dissected tissue uniformly carrying a heterozygous mutation. Further analyses with pure heterozygous samples, such as control cell lines, could be useful to calculate the standard error of this type of measurement for future experiments.

\section{Discussion}

The development of novel targeted therapies has created the need for molecular characterisation of cancers to allow more appropriate treatment decisions. We explored two approaches based on HRM and next-generation sequencing technologies to assess the mutational status of KRAS, BRAF and EGFR in diagnostic settings.

The HRM assay described herein successfully identified hotspot mutations of these genes in 120 FFPE diagnostic specimens. In CRC samples, the mutation frequencies of KRAS codon $12 / 13$ and BRAF V600E 


\begin{tabular}{|l|c|c|r|r|r|r|r|}
\hline Reference & Variant & Max & \multicolumn{1}{|c|}{$33 \mathrm{~K}$} & \multicolumn{1}{|c|}{$51 \mathrm{~K}$} & \multicolumn{1}{|c|}{$75 \mathrm{~K}$} & \multicolumn{1}{c|}{$81 \mathrm{~K}$} & $97 \mathrm{~K}$ \\
\hline KRAS & G12C & 35.68 & $0.00(9,193)$ & $0.00(11,919)$ & $0.00(10,622)$ & $0.00(9,327)$ & $35.68(11,226)$ \\
\hline KRAS & G12D & 38.90 & $0.00(9,193)$ & $0.00(11,919)$ & $0.01(10,622)$ & $38.90(9,327)$ & $0.00(11,226)$ \\
\hline KRAS & G12V & 22.80 & $0.00(9.193)$ & $22.80(11.919)$ & $0.00(10.622)$ & $0.00(9.327)$ & $0.00(11.226)$ \\
\hline
\end{tabular}

Sample 97K: c.34G>T

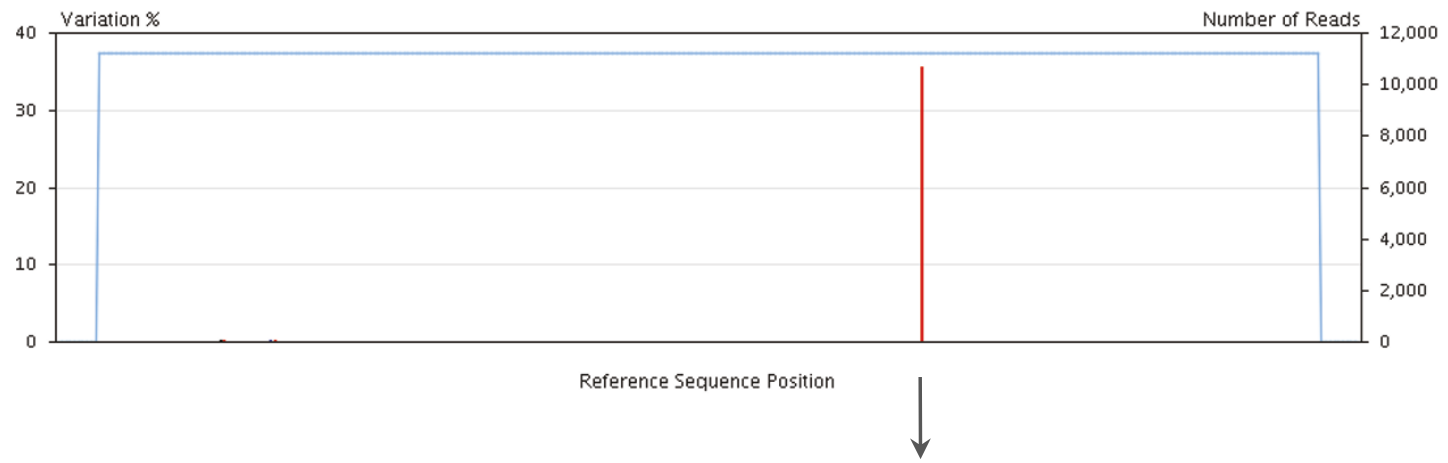

TAT AAGGCCT GCT GAAAAT GACT GAAT AT AAACT T GT GGT AGT T GGAGCT GGT GGC GTAGGCAAGAGT GCCT T GAC GAT AC TAT AAGGC CT GCT GAAAAT GACT GAAT AT AAACT T GT GGT AGT T GGAGCT GGT GGC GTAGGCAAGAGT GC C T T GAC GATAC TAT AAGGC CT GCT GAAAAT GACT GAAT AT AAACT T GT GGT AGT T GGAGCT T GT GGCGTAGGCAAGAGT GC CT T GAC GAT AC TATAAGGCCT GCT GAAAAT GACT GAATAT AAACTT GT GGT AGT T GGAGCT GGT GGCGTAGGCAAGAGT GC CTT GACGATAC TATAAGCCCTGCTGAAAATGACT GAATATAAACTTGT GTAGTTGGAGCTTGTGGCGTAGGCAAGAGT GCCTTGACGATAC

TATAAGGCCTGCT GAAAAT GACT GAATATAAACTTGTGGTAGTTGGAGCT GGTGGCGTAGGCAAGAGTGCCTTGACGATAC

Figure 4 Variants detected by ultra-deep pyrosequencing of KRAS amplicons. The variants frequency table (top) summarises the frequencies of the previously defined variants detected within each sample, with the corresponding number of combined reads shown between parentheses. Below, the plot of sequence variations detected in sample $97 \mathrm{~K}$ and a partial image capture of the global alignment, displayed as consensus reads, are shown as an example of 454 sequencing output. The only change detected within this sample is the known c.34G > T mutation (G12C).

were $44.3 \%$ and $13.0 \%$, respectively, and their mutual exclusiveness was confirmed. Our results are coincident with those reported previously [30,31]. In lung cancer, EGFR mutations were detected in $11.1 \%$ of samples, none of which was mutated for KRAS. Despite the small size and heterogeneity of our sample, this percentage is close to the $16.6 \%$ reported in a large-scale screening for EGFR mutations in Spanish lung cancer patients [5].

Compared to a commercially available mutation test, such as the DxS TheraScreen KRAS mutation kit (Qiagen), our HRM assay detected all KRAS mutations previously found. Moreover, our HRM KRAS mutation analysis has the advantage that it can be performed together with detection of $B R A F$ and EGFR mutations in the same assay.

As FFPE tissues are the most common clinical specimens available for mutation analysis, assessment of the analytical sensitivity of the KRAS HRM assay was performed with patient FFPE-derived DNA instead of control cell lines bearing known KRAS mutations. Using dilution series, the assay was able to detect $2.5 \%$ mutant alleles or $5 \%$ tumour cells carrying a heterozygous mutation. This analytical sensitivity is within the 1.5-6\% range obtained with cell lines in other KRAS assays based on standard PCR following HRM [30,32,33], and much higher than that of direct sequencing, which continues to be regarded as the "gold standard" although it requires a mutant allele threshold of $10 \%$ [34].

Unlike most published HRM studies, which identify wild type and mutant samples according to the normalised temperature-shifted differential plot, we based our analysis on the interpretation of melting peaks. We found this curve to be more sensitive and reproducible, as small variations between samples caused a spread of wild type curves around the baseline of the differential plot. Instead of being a drawback, the presence of multiple melting domains generates a particular curve morphology that differentiates mutant and wild type melting patterns more clearly, even with low amounts of mutant DNA, as seen in the KRAS assay.

Another strength of our assay is the use of a touchdown PCR covering a range of annealing temperatures (between $62^{\circ} \mathrm{C}$ and $54^{\circ} \mathrm{C}$ ) to ensure that all the primer pairs hybridise specifically to the template DNA and adequate amounts of PCR product are finally obtained. Then, the use of a wide melting interval $\left(72^{\circ} \mathrm{C}\right.$ to $\left.92^{\circ} \mathrm{C}\right)$ allows all the amplicons to melt, so they can be analysed together in a single plate, saving time and cost. 
Optimisation of the reaction volume to $10 \mu \mathrm{l}$ instead of $20 \mu \mathrm{l}$ could also be carried out.

The main limitation of our HRM assay is the need to sequence a few positive samples to identify the specific nucleotide alterations. When many types of mutations may exist within an amplicon, as in the case of KRAS exon 2, it is difficult to assign a melting profile to each one, even more so if, as we observed, the pattern varies with the amount of the mutant allele. Moreover, clinically important mutations and neutral variants generate almost identical curves and can be confused, as occurs with L858R and P848L mutations in EGFR codon 21 (not shown). Thus, direct Sanger sequencing is always necessary to avoid misdiagnosis. However, in a lower mutant allele concentration, Sanger sequencing may be insufficient to validate the results (Figure 2B), and a much higher sensitivity and accuracy may be necessary in some of the scenarios discussed above. We achieved our result with ultra-deep pyrosequencing of KRAS amplicons with GS Junior 454, which determined the frequencies of mutant alleles and confirmed the known KRAS genotypes. This sequencing experiment also demonstrated excellent performance in terms of throughput and reads per run. The five KRAS amplicons were similarly represented, with 9 to $12 \times 10^{3}$ reads per sample, an excess with respect to the depth of coverage required for accurate assessment of somatic mutations, considering that a $1 \%$ variation of a single-base change and multibase deletion will need 5,000-fold coverage to obtain a good statistical chance of 50 variation reads [35]. Moreover, the use of MIDs allowed massively parallel sequence analysis of multiple samples to be performed.

\section{Conclusions}

In conclusion, our HRM assay is a simple, robust and inexpensive method that allows multiple mutation hotspots to be rapidly screened and is thus highly suited to mutation detection in DNA derived from FFPE tissues. Ultra-deep pyrosequencing of KRAS amplicons with GS Junior 454 proved to be a highly sensitive and quantitative technique to analyse somatic mutations in cancer specimens, and which can also be used in a highthroughput assay.

\section{Acknowledgements \\ We thank lan Johnstone for the English revision and editing of the manuscript. \\ This work was supported by grants from Spanish Health Ministry (FIS) network RIRAAF (RD 07/0064).}

\footnotetext{
Author details

${ }^{1}$ Molecular Genetics Unit, Hospital de Terrassa, Ctra. Torrebonica, 08227 Terrassa, Spain. ${ }^{2}$ Pathology Service, Hospital de Terrassa, Ctra. Torrebonica, 08227 Terrassa, Spain. ${ }^{3}$ Oncology Service, Hospital de Terrassa, Ctra. Torrebonica, 08227 Terrassa, Spain. ${ }^{4}$ Department of Pharmacology,
}

Universidad de Extremadura, Av. Elvas, 06071 Badajoz, Spain. ${ }^{5}$ Allergy Service, Hospital Carlos Haya, PI. Hospital Civil, 29009 Málaga, Spain.

\section{Authors' contributions}

EB designed the study, carried out DNA extraction, designed and tested the primers, performed HRM and pyrosequencing studies, and drafted the manuscript. IJ obtained the FFPE sections from tumour samples and participated in the design of the study. $I H$ participated in HRM and pyrosequencing studies. MJG, MD and IM participated in HRM assays. BM carried out DNA extraction. AA participated in the design and coordination of the study. JAGA and MB participated in the validation of the results. MC conceived the study, participated in its design and coordination, and helped to draft the manuscript. All authors have read and approved the final manuscript.

\section{Competing interests}

The authors declare that they have no competing interests.

Received: 28 April 2011 Accepted: 24 September 2011

Published: 24 September 2011

\section{References}

1. Lynch TJ, Bell DW, Sordella R, Gurubhagavatula S, Okimoto RA, Brannigan BW, Harris PL, Haserlat SM, Supko JG, Haluska FG, Louis DN, Christiani DC, Settleman J, Haber DA: Activating mutations in the epidermal growth factor receptor underlying responsiveness of nonsmall-cell lung cancer to gefitinib. N Engl J Med 2004, 350(21):2129-2139.

2. Paez JG, Jänne PA, Lee JC, Tracy S, Greulich H, Gabriel S, Herman P, Kaye FJ, Lindeman N, Boggon TJ, Naoki K, Sasaki H, Fujii Y, Eck MJ, Sellers WR, Johnson BE, Meyerson M: EGFR mutations in lung cancer: correlation with clinical response to gefitinib therapy. Science 2004, 304(5676):1497-1500.

3. Pao W, Miller V, Zakowski M, Doherty J, Politi K, Sarkaria I, Singh B, Heelan R, Rusch V, Fulton L, Mardis E, Kupfer D, Wilson R, Kris M, Varmus H: EGF receptor gene mutations are common in lung cancers from "never smokers" and are associated with sensitivity of tumors to gefitinib and erlotinib. Proc Natl Acad Sci USA 2004, 101(36):13306-13311.

4. Shigematsu H, Lin L, Takahashi T, Nomura M, Suzuki M, Wistuba II, Fong KM, Lee H, Toyooka S, Shimizu N, Fujisawa T, Feng Z, Roth JA, Herz J, Minna JD, Gazdar AF: Clinical and biological features associated with epidermal growth factor receptor gene mutations in lung cancers. J Natl Cancer Inst 2005, 97(5):339-346.

5. Rosell R, Moran T, Queralt C, Porta R, Cardenal F, Camps C, Majem M, Lopez-Vivanco G, Isla D, Provencio M, Insa A, Massuti B, Gonzalez-Larriba JL, Paz-Ares L, Bover I, Garcia-Campelo R, Moreno MA, Catot S, Rolfo C, Reguart N, Palmero R, Sánchez JM, Bastus R, Mayo C, Bertran-Alamillo J, Molina MA, Sanchez JJ, Taron M, Spanish Lung Cancer Group: Screening for epidermal growth factor receptor mutations in lung cancer. $N$ Engl J Med 2009, 361(10):958-967.

6. Balak MN, Gong Y, Riely GJ, Somwar R, Li AR, Zakowski MF, Chiang A, Yang G, Ouerfelli O, Kris MG, Ladanyi M, Miller VA, Pao W: Novel D761Y and common secondary T790M mutations in epidermal growth factor receptor-mutant lung adenocarcinomas with acquired resistance to kinase inhibitors. Clin Cancer Res 2006, 12:6494-6501.

7. Kobayashi S, Boggon TJ, Dayaram T, Jänne PA, Kocher O, Meyerson M, Johnson BE, Eck MJ, Tenen DG, Halmos B: EGFR mutation and resistance of non-small-cell lung cancer to gefitinib. N Engl J Med 2005, 352:786-792.

8. Adjei AA: Blocking oncogenic Ras signaling for cancer therapy. $J$ Nat/ Cancer Inst 2001, 93(14):1062-1074.

9. Bos JL: ras oncogenes in human cancer: a review. Cancer Res 1989, 49(17):4682-4689.

10. Linardou H, Dahabreh IJ, Kanaloupiti D, Siannis F, Bafaloukos D, Kosmidis P, Papadimitriou CA, Murray S: Assessment of somatic k-RAS mutations as a mechanism associated with resistance to EGFR-targeted agents: a systematic review and meta-analysis of studies in advanced non-smallcell lung cancer and metastatic colorectal cancer. Lancet Oncol 2008, 9(10):962-972.

11. Marchetti A, Martella C, Felicioni L, Barassi F, Salvatore S, Chella A, Camplese PP, larussi T, Mucilli F, Mezzetti A, Cuccurullo F, Sacco R, Buttitta F: EGFR mutations in non-small-cell lung cancer: analysis of a large series of cases and development of a rapid and sensitive method 
for diagnostic screening with potential implications on pharmacologic treatment. J Clin Oncol 2005, 23(4):857-865.

12. Pollock PM, Harper UL, Hansen KS, Yudt LM, Stark M, Robbins CM, Moses TY, Hostetter G, Wagner U, Kakareka J, Salem G, Pohida T, Heenan P, Duray $P$, Kallioniemi O, Hayward NK, Trent JM, Meltzer PS: High frequency of BRAF mutations in nevi. Nat Genet 2003, 33:19-20.

13. Hingorani SR, Jacobtz MA, Robertson GP, Herlyn M, Tuveson DA: Suppression of BRAF V599E in human melanoma abrogates transformation. Cancer Res 2003, 63:5198-5202.

14. Di Nicolantonio F, Martini M, Molinari F, Sartore-Bianchi A, Arena S, Saletti P: Wild-type BRAF is required for response to panitumumab or cetuximab in metastatic colorectal cancer. J Clin Oncol 2008, 26(35):5705-5712.

15. Loupakis F, Ruzzo A, Cremolini C, Vincenzi B, Salvatore L, Santini D, Masi G, Stasi I, Canestrari E, Rulli E, Floriani I, Bencardino K, Galluccio N, Catalano V, Tonini G, Magnani M, Fontanini G, Basolo F, Falcone A, Graziano F: KRAS codon 61,146 and BRAF mutations predict resistance to cetuximab plus irinotecan in KRAS codon 12 and 13 wild-type metastatic colorectal cancer. Br J Cancer 2009, 101(4):715-721.

16. Bokemeyer C, Kohne C, Rougier P, Stroh C, Schlichting M, Van Cutsem E: Cetuximab with chemotherapy (CT) as first-line treatment for metastatic colorectal cancer (mCRC): analysis of the CRYSTAL and OPUS studies according to KRAS and BRAF mutation status. J Clin Oncol 2010, 28:15s, Abstract 3506

17. Wilson PM, Labonte MJ, Lenz HJ: Molecular markers in the treatment of metastatic colorectal cancer. Cancer J 2010, 16(3):262-272.

18. National Comprehensive Cancer Network., Guidelines for Colon and Rectal Cancer. v.1.2010

19. National Comprehensive Cancer Network., Non-Small Cell Lung Cancer Clinical Practice Guidelines. January 2011 update..

20. Keedy VL, Temin S, Somerfield MR, Beasley MB, Johnson DH, McShane LM, Milton DT, Strawn JR, Wakelee HA, Giaccone G: American Society of Clinical Oncology provisional clinical opinion: epidermal growth factor receptor (EGFR) Mutation testing for patients with advanced non-smallcell lung cancer considering first-line EGFR tyrosine kinase inhibitor therapy. J Clin Oncol 2011, 29(15):2121-2127.

21. van Krieken JH, Jung A, Kirchner T, Carneiro F, Seruca R, Bosman FT, Quirke P, Fléjou JF, Plato Hansen T, de Hertogh G, Jares P, Langner C, Hoefler G, Ligtenberg M, Tiniakos D, Tejpar S, Bevilacqua G, Ensari A: KRAS mutation testing for predicting response to anti-EGFR therapy for colorectal carcinoma: proposal for an European quality assurance program. Virchows Arch 2008, 453(5):417-431.

22. Taylor CF: Mutation scanning using high-resolution melting. Biochem SoC Trans 2009, 37(Pt 2):433-437.

23. NCBI/Primer - BLAST. [http://www.ncbi.n/m.nih.gov/tools/primer-blast]

24. DNA Melting - Stitch Profile. [http://stitchprofiles.uio.no].

25. The DINAMelt Web Server. [http://mfold.rna.albany.edu/?q = DINAMelt].

26. Ma ES, Wong $C L$, Law FB, Chan WK, Siu D: Detection of KRAS mutations in colorectal cancer by high-resolution melting analysis. J Clin Pathol 2009, 62(10):886-891.

27. Do H, Krypuy M, Mitchell PL, Fox SB, Dobrovic A: High resolution melting analysis for rapid and sensitive EGFR and KRAS mutation detection in formalin fixed paraffin embedded biopsies. BMC Cancer 2008, 8:142.

28. de Gunst MM, Gallegos-Ruiz MI, Giaccone G, Rodriguez JA: Functional analysis of cancer-associated EGFR mutants using a cellular assay with YFP-tagged EGFR intracellular domain. Mol Cancer 2007, 6:56.

29. Gonzalez-Bosquet J, Calcei J, Wei JS, Garcia-Closas M, Sherman ME, Hewitt S, Vockley J, Lissowska J, Yang HP, Khan J, Chanock S: Detection of somatic mutations by high-resolution DNA melting (HRM) analysis in multiple cancers. PLoS One 2011, 6(1):e14522.

30. Simi L, Pratesi N, Vignoli M, Sestini R, Cianchi F, Valanzano R, Nobili S, Mini E, Pazzagli M, Orlando C: High-resolution melting analysis for rapid detection of KRAS, BRAF, and PIK3CA gene mutations in colorectal cancer. Am J Clin Pathol 2008, 130(2):247-253.

31. Amado RG, Wolf $M$, Peeters $M$, Van Cutsem E, Siena S, Freeman DJ, Juan $T$, Sikorski R, Suggs S, Radinsky R, Patterson SD, Chang DD: Wild-type KRAS is required for panitumumab efficacy in patients with metastatic colorectal cancer. J Clin Oncol 2008, 26(10):1626-1634.

32. Krypuy M, Newnham GM, Thomas DM, Conron M, Dobrovic A: High resolution melting analysis for the rapid and sensitive detection of mutations in clinical samples: KRAS codon 12 and 13 mutations in nonsmall cell lung cancer. BMC Cancer 2006, 6:295.
33. Kramer D, Thunnissen FB, Gallegos-Ruiz MI, Smit EF, Postmus PE, Meijer CJ Snijders PJ, Heideman DA: A fast, sensitive and accurate high resolution melting (HRM) technology-based assay to screen for common K-ras mutations. Cell Oncol 2009, 31(3):161-167.

34. Ogino S, Kawasaki T, Brahmandam M, Yan L, Cantor M, Namgyal C, MinoKenudson M, Lauwers GY, Loda M, Fuchs CS: Sensitive sequencing method for KRAS mutation detection by Pyrosequencing. J Mol Diagn 2005, 7(3):413-421.

35. Genome Sequencer System - Application Note No. 5/February 2007, Amplicon Sequencing. [http://www.roche-applied-science.com].

Pre-publication history

The pre-publication history for this paper can be accessed here: http://www.biomedcentral.com/1471-2407/11/406/prepub

\section{doi:10.1186/1471-2407-11-406}

Cite this article as: Borràs et al.: Clinical pharmacogenomic testing of KRAS, BRAF and EGFR mutations by high resolution melting analysis and ultra-deep pyrosequencing. BMC Cancer 2011 11:406.

\section{Submit your next manuscript to BioMed Central and take full advantage of:}

- Convenient online submission

- Thorough peer review

- No space constraints or color figure charges

- Immediate publication on acceptance

- Inclusion in PubMed, CAS, Scopus and Google Scholar

- Research which is freely available for redistribution

Submit your manuscript at www.biomedcentral.com/submit
Biomed Central 